\title{
A review of causal inference in forensic medicine
}

\author{
Putri Dianita Ika Meilia ${ }^{1} \cdot$ Michael D. Freeman ${ }^{1} \cdot$ Herkutanto $^{2} \cdot$ Maurice P. Zeegers $^{1}$
}

Accepted: 13 January 2020 / Published online: 10 March 2020

(C) The Author(s) 2020

\begin{abstract}
The primary aim of forensic medical analysis is to provide legal factfinders with evidence regarding the causal relationship between an alleged action and a harmful outcome. Despite existing guides and manuals, the approach to formulating opinions on medicolegal causal inference used by forensic medical practitioners, and how the strength of the opinion is quantified, is mostly lacking in an evidence-based or systematically reproducible framework. In the present review, we discuss the literature describing existing methods of causal inference in forensic medicine, especially in relation to the formulation of expert opinions in legal proceedings, and their strengths and limitations. Causal inference in forensic medicine is unique and different from the process of establishing a diagnosis in clinical medicine. Because of a lack of tangibility inherent in causal analysis, even the term "cause" can have inconsistent meaning when used by different practitioners examining the same evidence. Currently, there exists no universally applied systematic methodology for formulating and assessing causality in forensic medical expert opinions. Existing approaches to causation in forensic medicine generally fall into two categories: intuitive and probabilistic. The propriety of each approach depends on the individual facts of an investigated injury, disease, or death. We opine that in most forensic medical settings, probabilistic causation is the most suitable for use and readily applicable. Forensic medical practitioners need, however, be aware of the appropriate approach to causation for different types of cases with varying degrees of complexity.
\end{abstract}

Keywords Causality $\cdot$ Causal inference $\cdot$ Intuitive causation $\cdot$ Probabilistic causation $\cdot$ Forensic medicine

\section{Introduction}

Forensic medicine (FM) refers to the discipline concerned with the application of medical knowledge and technology in legal proceedings [1-3]. Although the practice, definitions, and applications of FM vary widely by geographic and jurisdictional region [4], the most common primary aim of forensic medical analysis is to provide legal factfinders (i.e. judge or jury) with evidence regarding the causal relationship between an action allegedly committed by the accused (in a criminal matter) or defendant (in a civil matter) and a medically

Putri Dianita Ika Meilia

p.meilia@maastrichtuniversity.nl

1 Care and Public Health Research Institute (CAPHRI), Maastricht University Medical Center+, Universiteitssingel 40, 6229 ER Maastricht, the Netherlands

2 Department of Forensic Medicine and Medicolegal Studies, Faculty of Medicine, University of Indonesia, Jl. Salemba Raya No. 4, Salemba, Jakarta Pusat 10430, Indonesia observed harmful outcome (injury, disease, or death). The results of a causal analysis are usually presented to the court in the form of an expert opinion. A causal analysis opinion may address general causation (whether an exposure can cause the injury observed in an individual) or specific causation (whether the exposure did cause the injury observed in the individual), or both. Expert opinions regarding causal inference, especially specific causation, is an essential element in most legal actions associated with an injury, as they provide evidence of the connection between an alleged unlawful or negligent act committed by one party and an observed adverse health effect in another [5].

Despite existing guides and manuals [6-8], the approach to formulating opinions on medicolegal causal inference used by forensic medical practitioners, and how the strength of the opinion is quantified, remains an element of FM practice that is mostly lacking in an evidence-based or systematically reproducible method. In the practice of medicolegal autopsy, for example, cause-of-death determination is often performed by subjectively appointing $a$ cause of death found at the autopsy as the cause of death, making the determination idiosyncratic to the experience and personal thought processes of the 
individual clinician and potentially irreproducible by other similarly experienced clinicians $[9,10]$. In other circumstances encountered in an FM analysis, the causal assessment may be more challenging because of either insufficiency of the quantify or reliability of physical evidence or, conversely, a surfeit of findings with manifold and even mutually exclusive interpretations [11]. In order to move in the direction of both valid and repeatable causal conclusions, a technically correct and sufficiently complete forensic examination of evidence must be combined with the application of generally accepted causal methods.

In the present review, we sought to define and discuss the literature describing existing methods and approaches of causal inference used by forensic medical practitioners, especially in relation to the formulation of expert opinions in legal proceedings. The strengths and limitations of the various causal approaches identified in the review are also presented.

\section{Cause, causal relationship, and causation}

Forensic medical practitioners provide opinions for factfinders regarding the cause of death, injury, or disease on a routine basis, yet because the concept of causation is somewhat abstract (particularly when compared with other more widely-known medical concepts, such as "diagnosis") the definition of what constitutes a cause is somewhat esoteric. The history of the study of injury and disease causality is tortuous and interdisciplinary, crossing from philosophy into science and medicine, and ultimately finding a home primarily in epidemiology. Many pre-eminent scientists and philosophers of their day, including Galileo Galilei, Karl Popper, David Hume, Bertrand Russell, Kenneth Rothman, John Stuart Mill, Robert Koch, and Austin Bradford Hill, have described various definitions of what a cause is, and/or how to demonstrate that a causal relationship is present [13].

In the current era, a cause is often defined as an antecedent event or condition which is necessary for the manifestation of the effect at the moment it occurred. Without the cause, the effect either would not have occurred at all or would have occurred later, given that other conditions are fixed [12]. Notwithstanding this simple definition, a cause can also be deemed as an exposure that only increases the probability of an effect $[13,14]$. There are three common attributes or properties of a cause, i.e. association (meaning that the effect occurs more often among those who are exposed than those who are not exposed), temporal order, and asymmetric direction of change [13].

A definition that is often used in medicolegal investigations of causation is that of the probabilistic cause (i.e. an antecedent exposure [A] which increases the probability of the occurrence of an effect [B]) in a counterfactual setting. A counterfactual is a hypothetical scenario that is contrary to the fact or reality, i.e. what would have happened if a different exposure had occurred (A' instead of A, everything else being constant) [15]. There are 4 types of (causal) relationships that may exist between $\mathrm{A}$ and $\mathrm{B}$, which are not necessarily mutually exclusive, as follows: (1) A causes B, (2) B causes A, (3) A and B have a common cause, and (4) A and B are not causally related [16].

The main difficulty in establishing causation is that causal relationships are unobservable; past events can no longer be observed [17]. Causation can only ever be known through inductive inference; it can never be directly demonstrated [18]. What we can do is evaluate the attributes of a potential cause or assess specific criteria of causation. Causation is always a judgment; even when we think that a causal relationship exists, there is no guarantee that we are right [14]. All existing models/approaches to causal evaluation are to a certain degree based in Hill's viewpoints, which were designed to assess the causal relationship of observed associations in populations, in part to determine if they are overtly spurious or not [19]. Temporal sequence is the only causal element that must be present in all cases. This relationship is, however, unidirectional; as the presence of an appropriate temporal sequence only demonstrates coincidence when a causal relationship is deemed implausible according to known scientific principles.

\section{Causal inference}

Causal inference is a unique type of scientific reasoning; there are no fixed set of causal criteria which can establish the validity of an inference [12]. It is a scientific judgement about the probability of a particular hypothesis based on the evaluation and weighting of various types of evidence [20]. Currently, causal inference is not part of the formal medical curriculum [21] because it is commonly considered as an innate ability of doctors to form logical conclusions based on their examinations. Actually, it is an acquired skill [22], which requires sufficient (medical) background knowledge and a lot of practice.

There are three categories of approach to probabilistic inference, i.e. forecasting, back-casting, and attribution [23]. Forecasting is the probability of an outcome given a particular exposure, whereas back-casting is the probability of an exposure given a specific outcome. Both are conditional statements and are sometimes referred to as "Effects of Causes (EoC)," and both are commonly used in medical science, particularly epidemiology. Attribution, on the other hand, is the probability that the outcome would not have occurred if it were not for a particular exposure. As such, attribution is a counterfactual statement and is referred to as "Causes of Effects (CoE)."

A counterfactual is a hypothesis of what would have happened under conditions which are contrary to actual conditions [24]. In other words, we try to envision what would the 
outcome be if B happened instead of A. We specify the counterfactual world by altering the suspected cause and then compare it to the factual circumstances [25]. For example, would the driver in a head-to-head car collision have died at that moment if he had worn a seatbelt? In assessing counterfactuals, we need to specify sufficiently-well defined versions of the potential outcome and its counterfactual contrast, given the circumstances, by taking all available knowledge/ evidence into account [26-30] and assuming a ceteris paribus condition, i.e. all other things or conditions being equal [31]. Because a counterfactual condition cannot be observed directly, and counterfactual outcomes cannot be determined in an individual, we need a substitute from which we can infer it. This substitute can either be a different target population or a different period [24, 32].

\section{General versus specific/individual causation}

The basic steps of causation analysis consist of determining general ('can-it' and 'does-it') and specific/individual ('did-it') causation [33]. Any individual causal analysis must consider general causation before trying to answer the question of specific causation, i.e. 'ruling in' the alleged causal agent before 'ruling out' other possible causes [34]. General causation is typically addressed at a population or pathophysiological level. This means that the plausibility of the relationship is established either via epidemiologic studies demonstrating an increased risk of injury from the exposure, or the injury is plausibly associated with the exposure despite the lack of epidemiologic evidence. The latter relationship may be assessed via some of the Hill criteria that address the plausibility of a causal relationship (e.g. coherence, analogy, specificity, etc.). Specific (individual) causation addresses whether the specific exposure was the cause of the diagnosed injury or disease in is the subject of discussion in many legal proceedings [18].

Specific causation is drawn from group-to-individual (G2i) inference based on the following assumptions: the risk estimate comes from a valid study, the individual is sufficiently similar to the study subjects with respect to important risk factors, the putative cause does not cause acceleration of outcome or provide protective effect and operates independently $[35,36]$. G2i inference can be justified if the individual possesses no features which make him/her more or less susceptible to the putative exposure's ability to cause the outcome in question than other members of the population/reference group. In other words, the affected individual must be comparable with regard to critical, and potentially confounding, characteristics, and can thus be treated as randomly selected from the population [18, 37-40].
Probability and the probability of causation (PC)

Probability reflects the degree of (un)certainty or conviction of the truth of an assertion for a given set of facts (conditional probability). Probabilistic causation uses Bayesian reasoning, which tells us what we want to know given what we do know, which are known as its 'conditions' and can be a combination of data (objective probability) and experience or knowledge (subjective probability) [41-43]. To obtain a correct value of probability, we must avoid vagueness in the causal analysis by clearly defining the terms and the relationships between the terms in the causal model [44].

If we want to express probabilities in words, we must ensure that we use the same words for the same values consistently. As an effort to clarify the meaning of probabilities in court, forensic scientists have often used numbers (quantitative explanation) followed by a verbal/qualitative interpretation [42, 45]. For example, a PC of $>50 \%$ is often stated as "more likely than not," a PC of $>98 \%$ is sometimes used to indicate that something is "beyond reasonable doubt," or using the term "to a reasonable degree of scientific certainty" to convey the general impression of confidence regarding their expert opinion. This method is, however, not without problems. Besides having no scientific meaning, those terms might mislead legal factfinders about the level of objectivity involved in the analysis, as well as its reliability and limitations in reaching an individualized conclusion [46].

Probabilities can be compared in different ways, e.g. by calculating the difference between two incidences (i.e. the risk difference (RD) or attributable risk (AR)) or by dividing them (i.e. the relative risk or risk ratio (RR)) [41]. The likelihood ratio is a ratio of two probabilities, i.e. the probability of the evidence supposing one hypothesis is true divided by the probability of the evidence if an alternative hypothesis is correct. The likelihood ratio can only be useful in comparing two hypotheses if they are mutually exclusive and reflect the opposing standpoints of the hypotheses [42].

The probability of causation (PC) expresses the amount of causation attributable to a component cause, which is equal to the reduction of the risk of the condition in a population that is not exposed to the cause. It should never be interpreted as the probability that a putative cause is the single cause of the effect in an individual [30]. There are dissenting opinions about the bounds of the PC in specific causation. First, some opine that epidemiological evidence can be used to estimate a lower bound on the probability of causation (PC: $\mathrm{PC} \geq 1-(1 / \mathrm{RR})$ ). The PC can then be used to fulfil the but-for test on the balance of probabilities [18]. The but-for test itself can be described in simple terms as follows: but-for the exposure or putative cause, would the individual still have the disease or experienced the injury at the same time, everything else being constant? The test, therefore, basically asks a counterfactual 
question, which is a hypothetical scenario that is contrary to the fact or reality. Another opinion is that inference about $\mathrm{CoE}$ from epidemiological data is usually presented as a PC with upper and lower bounds. As such, it contains triple uncertainties, i.e. it is a probability with interval bounds, which are imprecise themselves [47]. Yet another opinion is that because the PC itself is the degree of (un-)certainty in considering the defined counterfactual conditions based on his/her present knowledge of the facts it is unnecessary to add bounds to it, which will only add uncertainties to an uncertainty. If there is new knowledge, the PC can be adjusted to reflect the current state of belief [48].

\section{The role of forensic medical expert opinions in legal causal analysis}

Causal analysis plays a vital part in establishing liability [5]. There are two aspects of causation, i.e. factual/cause-in-fact causation and proximate/legal causation $[12,49]$. The role of forensic medical expert opinions in legal proceedings is to help determine factual causation by assessing probabilities for the "but-for" test, which are then used by the legal factfinders to establish a proximate cause in the form of proportional liabilities [6, 50-52]. An essential role of the forensic medical expert is to quantify the PC, which denotes the probability that the defendant's act caused the effect in the claimant [53]. A primary obstacle in drawing causal inferences is the binary format of the legal question for causation. It is based on the 'but-for' test and demands a simple yes or no answer [30].

The most important principle to be remembered is that expert opinions must be useful to the legal fact finder. Thus, they must be applicable to the individual case at hand [54]. Expert opinions should be informative, or at least not be misleading and/or speculative [34]. A helpful forensic medical expert opinion has several features: (1) it provides a concise and straightforward answer, (2) it states the reasons or justifications for a particular opinion which can be upheld in court, (3) in cases where it is impossible to provide a definite answer, it gives the best possible explanation on a 'balance of probabilities', and (4) it must be clearly and appropriately worded to prevent any ambiguities $[6,40,42,55]$.

Often, courts must rely on expert testimony that is not much more than an experience-based clinical judgment. When there is a difference in opinion between experts, the legal fact finder should be able to evaluate whether those opinions are based on valid and rational approaches. Therefore, any methods used by an expert should be transparent and justifiable based on the best available scientific evidence $[33,56]$. It is perfectly acceptable for experts to base their claims on assumptions if those assumptions are made transparent. In that way, others can judge whether they are plausible [57]. The Daubert principle might be considered as demand for 'evidence-based (expert) evidence', as it asks judges to act as gatekeepers by ensuring that (forensic) expert evidence to be admitted in court is not only relevant but also reliable $[58,59]$. This can be achieved through the development of 'clinical practice guidelines' in formulating expert opinions [59].

\section{Existing medicolegal causal analysis approaches}

Medicolegal causal analysis is the process of determining the nature and probability of a relationship between a putative cause and a claimed effect. Generally, the complex process of medicolegal causal analysis is poorly conceptualized, not standardized, and only supported by the expertise or experience of the individual expert [60]. Currently, there exist several approaches to medicolegal causal analysis in forensic medicine. All approaches generally fall into two categories, i.e. either they are intuitive or probabilistic. The presence of Hill's viewpoints marked the transition from the purely intuitive approaches to the more systematic, analytic approaches, which then led to the conception of the probabilistic ones. Table 1 summarizes those approaches, their strengths and weaknesses, as well as the type of cases for which they are appropriate.

\section{Discussion}

Causal inference in forensic medicine is different from the process of establishing a diagnosis in clinical medicine. Diagnoses in clinical medicine are prospective in nature; i.e. they move from diagnosis to a specific clinical decision (e.g. a treatment) and, thus, have an empirical aspect allowing for observation of and patient feedback on the efficacy of the strategy, and thereby the correctness of the diagnosis. Gold standards are often available for clinical practice, (an example is an autopsy to confirm the presence of antemortem diagnosis), and the use of such standards leads to broadly accepted standards for diagnosis and treatment. In contrast with clinical medicine, forensic medical investigations are all conducted retrospectively. One of the central goals of a forensic medical investigation is to assess the causal relationship between a particular action of interest and an adverse injury or disease health event that has occurred prior to the investigation. As causal investigations are always retrospective, the cause of an injury or disease can never be observed or measured directly (like a diagnosis). An additional facet of causal investigation in forensic medicine is that there are no actual gold standards, unlike in clinical medicine, against which one can ascertain the validity of a causal inference [9]. Whether or not a causal relationship is present between an investigated action and a 


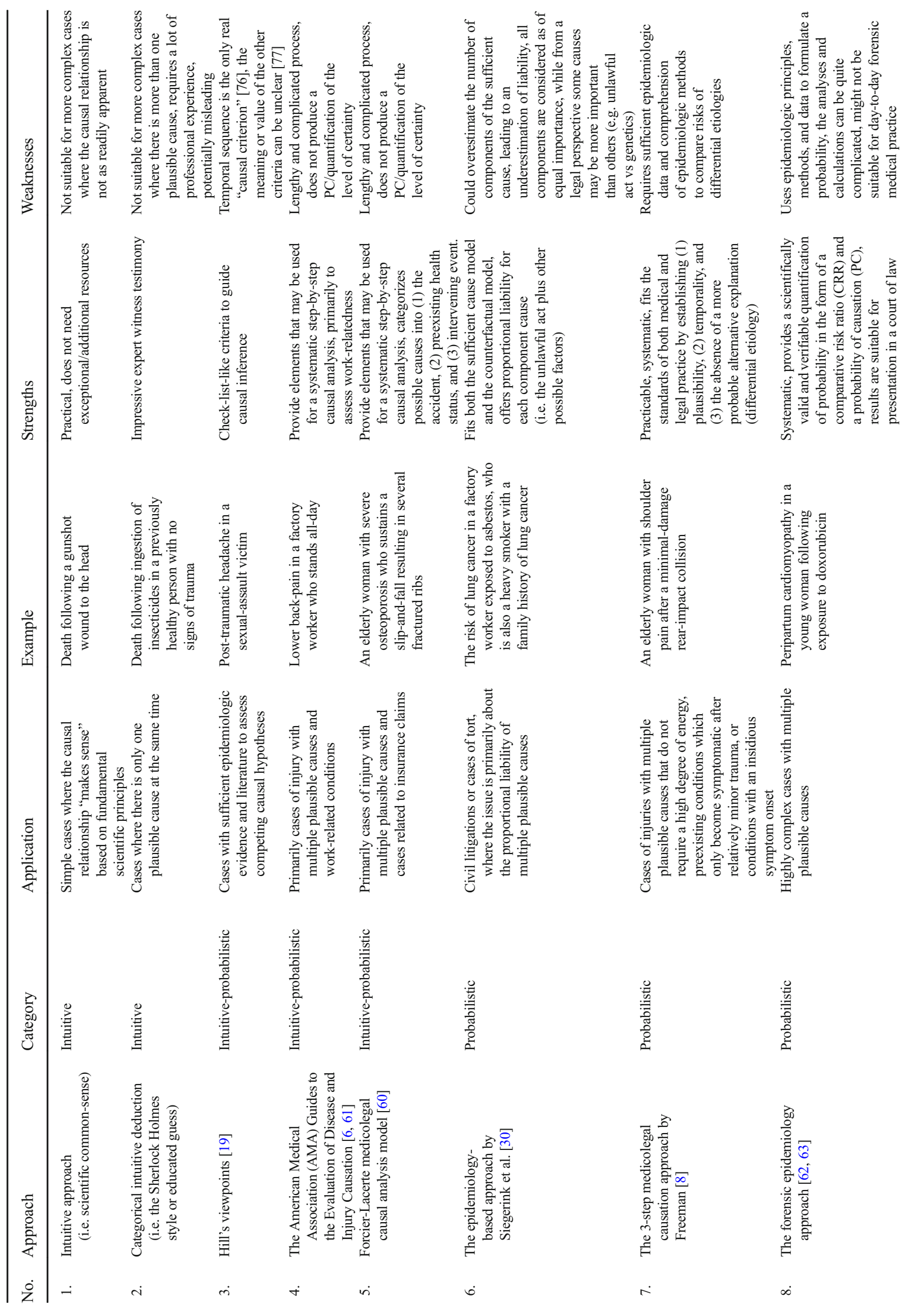


subsequently observed disease or injury, as well as the strength of the relationship, must be determined inferentially, via weighing and comparing of risks [62].

In addition to the inherent subjectivity of causation opinions, several additional factors threaten the validity and reliability of forensic medical expert opinions. First, forensic medical practitioners tend to rely more on experience and individual customary practice in formulating their opinion than on evidence or consensus-based practices [64, 65]. Additionally, the strategy used in formulating expert opinions varies substantially between experts [66, 67]. Expert inferential opinions, particularly those regarding causation, often involve a conclusory leap from objective findings to subjective conclusions, without a clearly defined strategy of how the former led to the latter. The reliability and repeatability of final opinions are thus threatened by to the idiosyncrasies of the individual expert, making it difficult for factfinders to judge the accuracy of forensic medical expert opinions, primarily when they address complex issues of causality [65, 68, 69].

To improve the reliability and repeatability of expert opinions, we propose that all forensic medical practitioners should have an arsenal of various approaches to establish causation at their disposal in daily practice. This is not to say that all causal determinations require an added layer of complexity to increase their validity. In obvious cases (e.g. cause of death after a decapitation injury) common sense is a sufficient basis for a causal determination since it is incompatible with life. In more complex cases (e.g. blunt head trauma in an elderly individual with evidence of myocardial infarction and alcohol intoxication) a more robust and detailed approach is necessary in order to minimize the impact of speculation on a causal conclusion [70]. Because of a lack of tangibility inherent in causal analysis, even the term "cause" can have inconsistent meaning when used by different practitioners examining the same evidence. If a forensic medical practitioner concludes that "the cause of death was X", is it meant that without X the death would not have occurred? Or that only once $X$ was combined with $\mathrm{Y}$ and $\mathrm{Z}$ that $\mathrm{X}$ became a "cause" of death. Does the latter opinion mean that $X$ by itself could not have caused the death, or that $\mathrm{X}, \mathrm{Y}$ and $\mathrm{Z}$ were all independent explanatory causes for the death? In the example given above for the complex causation scenario, one expert may choose the head trauma as the cause of death, while another expert may choose the myocardial infarction, and a third expert may choose all three acting in concert. In other words, A causes B, if the probability of B given $\mathrm{A}$ is higher than the probability of $\mathrm{B}$ in the absence of $\mathrm{A}$ (everything else being constant) [15]. This causal inference based on counterfactual probability is suitable for use and readily applicable in legal proceedings because (1) it acknowledges the fact that a $100 \%$ degree of certainty for causality is unachievable, (2) it allows multiple causation (because a condition must only raise the probability of an event and does not have to be a sufficient cause for it, i.e. it is a contributory cause), (3) based on the 'but-for' concept, i.e. without the cause the outcome would not have occurred at all or at that particular time, and (4) it can be expressed as a probability of causation (PC) which can be calculated using epidemiological data from a population that is comparable to the affected individual $[57,71]$.

Currently, we are developing a causal analysis approach to be used in daily practice which is based on counterfactual inference. We hope that this new approach will provide simple guidance, perform adequately, and be scientifically sound, and yet still be practical and easy enough to communicate to medical laypersons.

\section{Conclusion}

Currently, there exist several different approaches to medicolegal causal analysis, ranging from the simple, intuitive approach to complex calculations of the probability of causation based on Bayesian principles. Every approach has its own strengths and limitations, and thus forensic medical practitioners should employ the appropriate approach for different types of cases with varying degrees of complexity.

\section{Key points}

1. Causal inference is a routine task in forensic medicine that is distinct from clinical diagnosis.

2. A variety of guides exist for causal inference, with various strengths and limitations.

3. A causal inference approach in forensic medicine is either intuitive or probabilistic.

4. There is no causal inference approach that can be applied universally.

5. Forensic medical practitioners must choose the appropriate approach for each case.

Funding Information This work was supported by the Indonesia Endowment Fund for Education (LPDP) scholarship body as part of a Doctoral Scholarship Program.

\section{Compliance with ethical standards}

Conflict of interest All authors provide medico-legal consultation services.

Research involving human participants and/or animals Not applicable.

Informed consent None sought.

Open Access This article is licensed under a Creative Commons Attribution 4.0 International License, which permits use, sharing, adaptation, distribution and reproduction in any medium or format, as long as you give appropriate credit to the original author(s) and the source, 
provide a link to the Creative Commons licence, and indicate if changes were made. The images or other third party material in this article are included in the article's Creative Commons licence, unless indicated otherwise in a credit line to the material. If material is not included in the article's Creative Commons licence and your intended use is not permitted by statutory regulation or exceeds the permitted use, you will need to obtain permission directly from the copyright holder. To view a copy of this licence, visit http://creativecommons.org/licenses/by/4.0/.

\section{References}

1. Madea B. History of forensic medicine - A brief introduction. In: Madea B, editor. History of forensic medicine. Berlin: Lehmanns Media, GmbH; 2017. p. 3-27.

2. Pinheiro J. Introduction to forensic medicine and pathology. In: Schmitt A, Cunha E, Pinheiro J, editors. Forensic anthropology and medicine: complementary sciences from recovery to cause of death. Totowa: Humana Press Inc.; 2006. p. 13-38.

3. Smith S. The history and development of forensic medicine. BMJ. 1951:1:599-607.

4. Meilia PDI, Freeman MD, Herkutanto, Zeegers MP. A review of the diversity in taxonomy, definitions, scope, and roles in forensic medicine: implications for evidence-based practice. Forensic Sci Med Pathol. 2018;14:460-8.

5. Honore A. Principles and values underlying the concept of causation in law. In: Mendelson D, Freckelton IR, editors. Causation in law and medicine. New York: Routledge; 2016. p. 3-13.

6. American Medical Association. In: Melhorn JM, Talmage JB, Ackerman III WE, Hyman MH, editors. AMA guides to the evaluation of disease and injury causation. 2nd ed. Chicago: American Medical Association; 2014.

7. Adams VI. Guidelines for reports by autopsy pathologists. Tampa: Humana Press Inc.; 2008.

8. Freeman MD. A practicable and systematic approach to medicolegal causation. Orthopedics. 2018;41:70-2.

9. Cordner S. Cause in forensic pathology: the cause and manner of death. In: Mendelson D, Freckelton IR, editors. Causation in law and medicine. New York: Routledge; 2016. p. 289-308.

10. Cordner S. Deciding the cause of death after necropsy. Lancet. 1993;341:1458-61.

11. Davison AM, Leadbeatter S. Confession of ignorance of causation in coroners' necropsies - a common problem? J Clin Pathol. 1996;49:439-43.

12. Rothman KJ, Greenland S. Causation and causal inference in epidemiology. Am J Public Health. 2005;95:S144-50.

13. Susser M. What is cause and how do we know one? A grammar for pragmatic epidemiology. Am J Epidemiol. 1991;133:635-48.

14. Mumford S, Anjum RL. Causation: a very short introduction. Oxford: Oxford University Press; 2013.

15. Parascandola M, Weed DL. Causation in epidemiology. J Epidemiol Community Health. 2001;55:905-12.

16. Bird A. The epistemological function of Hill's criteria. Prev Med (Baltim). Elsevier Inc.; 2011;53:242-5.

17. Young TW. The Sherlock effect: how forensic doctors and investigators disastrously reason like the great detective. Boca Raton: CRC Press; 2018.

18. Broadbent A. Causation in epidemiology and law. In: Zeegers MP, Freeman MD, editors. Forensic epidemiology: principles and practice. London: Academic Press; 2016. p. 112-30.

19. Morabia A. On the origin of Hill's causal criteria. Epidemiology. 1991;2:367-9.
20. Vandenbroucke JP, Broadbent A, Pearce N. Causality and causal inference in epidemiology: the need for a pluralistic approach. Int $\mathrm{J}$ Epidemiol. 2016;45:1776-86.

21. Freeman MD, Franklin F. Medical negligence investigation. In: Freeman MD, Zeegers MP, editors. Forensic epidemiology: principles and practice. London: Academic Press; 2016. p. 351-70.

22. Jenicek M. Do we need another discipline in medicine? From epidemiology and evidence-based medicine to cognitive medicine and medical thinking. J Eval Clin Pract. 2015;21:1028-34.

23. Cuellar M. Causal reasoning and data analysis: problems with the abusive head trauma diagnosis. Law Probab Risk. 2017;16:223-39.

24. Maldonado G, Greenland S. Estimating causal effects. Int J Epidemiol. 2002;31:422-9.

25. Stapleton J. Choosing what we mean by causation in the law. Miss Law Rev. 2008;73:433-80.

26. Teigen KH. When the unreal is more likely than the real: post hoc probability judgments and counterfactual closeness. Think Reason. 1998;4:147-77.

27. Scheines R. Causation, truth, and the law. Brook Law Rev. 2008:116.

28. Schaffer J. Contrastive causation in the law. LT. 2010;16:259-97.

29. Hernán MA. Does water kill? A call for less casual causal inferences. Ann Epidemiol. 2016;26:674-80.

30. Siegerink B, den Hollander W, Zeegers MP, Middelburg R. Causal inference in law: an epidemiological perspective. Eur J Risk Regul. 2016;7:175-86.

31. Dawid AP, Musio M, Murtas R. The probability of causation. Law Probab Risk. 2017;16:163-79.

32. Höfler M. The Bradford Hill considerations on causality: a counterfactual perspective. Emerg Themes Epidemiol. 2005;2:11.

33. Gots RE. Medical causation and expert testimony. Regul Toxicol Pharmacol. 1986;6:95-102.

34. Sanders J. Applying Daubert inconsistently? Proof of individual causation in toxic tort and forensic cases. Brook Law Rev. 2010;75:1367-404.

35. Committee on the Development of the Third Edition of the Reference Manual on Scientific Evidence. Reference Manual on Scientific Evidence: Third Edition. Washington, D.C.: National Academies Press; 2011.

36. Faigman DL, Monahan J, Slobogin C. Group to individual (G2i) inference in scientific expert testimony. Univ Chicago Law Rev. 2014;81:417-80.

37. Dawid AP, Faigman DL, Fienberg SE. Authors' response to comments on fitting science into legal contexts: assessing effects of causes or causes of effects? Sociol Methods Res. 2014;43:416-21.

38. Miller C. Causation in personal injury law: the case for a probabilistic approach. Topoi. 2014;33:385-96.

39. Dawid P. On individual risk. Synthese. 2017;194:3445-74.

40. Freeman MD, Kohles SS. Applications and limitations of forensic biomechanics: a Bayesian perspective. J Forensic Legal Med. 2010;17:67-77.

41. Zeegers MP, Bours MJL, Freeman MD. Methods used in forensic epidemiologic analysis. In: Freeman MD, Zeegers MP, editors. Forensic epidemiology: principles and practice. London: Elsevier Inc.; 2016. p. 71-110.

42. Robertson B, Vignaux GA, Berger CEH. Interpreting evidence: evaluating forensic science in the courtroom. 2nd ed. West Sussex: John Wiley \& Sons Ltd.; 2016.

43. Lucena-Molina JJ. Epistemology applied to conclusions of expert reports. Forensic Sci Int. 2016;264:122-31.

44. Dawid AP. Causal inference without counterfactuals: rejoinder. J Am Stat Assoc. 2000;95:444-8.

45. Weinstein JB, Dewsbury I. Comment on the meaning of "proof beyond a reasonable doubt”. Law Probab Risk. 2008;5:167-73. 
46. National Commission on Forensic Science. Recommendations to the Attorney General regarding use of the term "reasonable scientific certainty." 2016. pp. 1-2.

47. Dawid AP, Musio M, Fienberg SE. From statistical evidence to evidence of causality. Bayesian Anal. 2016;11:725-52.

48. Biedermann A, Bozza S, Taroni F, Aitken C. Reframing the debate: a question of probability, not of likelihood ratio. Sci Justice. 2016;56:392-6.

49. Cox LA. Modernizing the Bradford Hill criteria for assessing causal relationships in observational data. Crit Rev Toxicol. 2018;48:1-31.

50. Sobczak F. Proportionality in tort law a comparison between Dutch and English laws with regard to the problem of multiple causation in asbestos-related cases. Eur Rev Private Law. 2010;6:1155-79.

51. Jerrold L. Possibility, probability, and causation: a study of proximate causation. Am J Orthod Dentofac Orthop. 2014;145:836-8.

52. Lin P, Gill JR. Delayed homicides and the proximate cause. Am J Forensic Med Pathol. 2009;30:354-7.

53. Faure M, Visscher L, Zeegers M, Freeman MD. The role of the expert witness. In: Zeegers MP, Freeman MD, editors. Forensic epidemiology: principles and practice. London: Academic Press; 2016. p. 132-47.

54. Dawid AP, Faigman DL, Fienberg SE. Fitting science into legal contexts: assessing effects of causes or causes of effects? Sociol Methods Res. 2014;43:359-90.

55. Sullivan JD. The medico-legal expertise: solid medicine, sufficient legal and a measure of common sense. McGill J Med. 2006;9:14751 .

56. National Research Council. The ethics of expert testimony. Age Expert Testimony Sci Court. Washington, D.C.: National Academy Press; 2002. pp. 27-9.

57. Pearl J, Mackenzie D. The book of why: the new science of cause and effect. New York: Basic Books; 2018.

58. Cooley C, Oberfield G. Increasing forensic evidence's reliability and minimizing wrongful convictions: applying Daubert isn't the only problem. Tulsa Law Rev. 2007;43:285-380.

59. Cole S. Toward evidence-based evidence: supporting forensic knowledge claims in the post-Daubert era. Tulsa Law Rev. 2007;43:263-83.
60. Lacerte M, Forcier P. Medicolegal causal analysis. Phys Med Rehabil Clin N Am. 2002;13:371-408.

61. Barth RJ. Determining injury-relatedness, work-relatedness, and claim-relatedness. AMA Guides Newsletter. 2012:1-12.

62. Freeman MD, Zeegers M. Principles and applications of forensic epidemiology in the medicolegal setting. Law Probab Risk. 2015;14:269-78.

63. Freeman MD, Rossignol AM, Hand ML. Forensic epidemiology: a systematic approach to probabilistic determinations in disputed matters. J Forensic Legal Med. 2008;15:281-90.

64. Colville-Ebeling B, Freeman M, Banner J, Lynnerup N. Autopsy practice in forensic pathology - evidence-based or experiencebased? A review of autopsies performed on victims of traumatic asphyxia in a mass disaster. J Forensic Leg Med. Elsevier Ltd; 2014;22:33-36.

65. Gee DJ. Reaching conclusions in forensic pathology. Med Sci Law. 1995;35:12-6.

66. The National Confidential Enquiry into Patient Outcome and Death (NCEPOD). The Coroner's autopsy: Do we deserve better? A report of the National confidential enquiry into patient outcome and death. NCEPOD. London; 2006.

67. Committee on identifying the needs of the forensic sciences community national research council. Strengthening forensic science in the United States: A path forward. Washington, D.C.: The National Academies Press; 2009.

68. Ong BB, Milne N. Quality assurance in forensic pathology. Malays J Pathol. 2009;31:17-22.

69. Obenson K, Wright CM. The value of $100 \%$ retrospective peer review in a forensic pathology practice. J Forensic Legal Med. 2013;20:1066-8.

70. Pollanen MS. Deciding the cause of death after autopsy - revisited. J Clin Forensic Med. 2005;12:113-21.

71. Höfler M. Causal inference based on counterfactuals. BMC Med Res Methodol. 2005;5:1-12.

Publisher's note Springer Nature remains neutral with regard to jurisdictional claims in published maps and institutional affiliations. 